\title{
Smart Electric Meter Deployment in Tanzania: A Survey
}

\author{
Theresia B Maziku, Kwame S Ibwe ${ }^{1^{*}}$, Abdi Abdalla and Ellen A Kalinga \\ College of Information and Communication Technologies, University of Dar es Salaam, P. O. \\ Box 33335, Dar es Salaam, Tanzania \\ Corresponding author,e-mail: kwame.ibwe@gmail.com
}

Received 6 Aug 2021, Revised 11 Nov 2021, Accepted 16 Nov 2021, Published Dec 2021

DOI: https://dx.doi.org/10.4314/tjs.v47i5.21

\begin{abstract}
Using information and communication technologies (ICT) to make the electrical power network intelligent and smarter (smart grid) has been the focal point in transforming electrical power industry. The idea behind smart grid is to transform the Tanzanian power sector into a secure, adaptive, sustainable, and digitally enabled ecosystem that provides reliable and quality energy for all with active participation of stakeholders. Smart metering is a central segment in realizing smart grid. However, a big question is whether Tanzanian power stakeholders are ready for smart metering technology investments for household applications. Operation and maintenance of a smart metering solution is a relatively new business in Tanzania and requires investment in resources and capacity building. A case study was conducted at the utility company in Dar es Salaam offices, to investigate the deployment status and services offered. Fixed tariff rates, high cost, low rates on returns of investment and non-customization of the features, were some of the shortcomings identified by the study in terms of non-deployment in residential homes. Further, the authors, propose development of standardization document for smart metering technologies and the adoption of software based smart meter for residential applications using Internet of Things platform. Its low cost of development and ease installation would be ideal for residential applications.
\end{abstract}

Keywords: Smart grid, Utility Company, Smart meter, Advanced Metering Infrastructure, Deployment Status.

\section{Introduction}

The Tanzania power system master plan targeted increase per capita electricity consumption from $377 \mathrm{kWh}$ in 2020/21 to $490 \mathrm{kWh}$ by $2025 / 26$ (PSMP 2020). This results from the extended distribution network, rural electrification drive through Rural Energy Agency (REA), revival of dormant industries, formation of new businesses, high urbanization rate and mushrooming of new power-hungry buildings. The potential energy demand by 2040 is estimated to be as high as $40 \mathrm{GW}$ out of which the renewable energy potential that can be exploited till 2040 is around $6 \mathrm{GW}$ (PSMP 2020). In Tanzania, the power system of this size growing at a rate of 10-15 per cent a year with an increased share of renewable energy requires smarter systems to manage it efficiently and ensure its stability and reliability, and optimize energy costs. Thus, smart electric grid which include automatic collection of Information using Communication Technologies (ICTs) will enable the utility company to modernize the way the electric network operates and managed ( El Houda et al. 2020, Dileep 2020).

Hence, the modernization of the legacy electric grid to Smart grid at the distribution side, requires an advanced electronic device called a Smart meter to be installed in each 
consumer's location to replace the traditional meter reading device (Avancini et al. 2020). This device enables two-way communications between the meter and utility company through advanced metering infrastructure (AMI) (Omole et al. 2016, Caropreso et al. 2018). AMI is the collective term to describe the whole infrastructure from smart meter to two way-communication network to control center equipment and all the applications that enable the gathering and transfer of energy usage information in near real-time (Mohassel et al. 2014, Abate et al. 2019, Al-Turjman and Abujubbeh 2019). The installation of an AMI is looked upon as a bridge to the construction of smart grids and smart meters are an integral part of the AMI (NEP 2015). This provides a variety of fine-grained data collections which were difficult to obtain in the legacy system. Thus, besides enabling a more accurate fine-grained power data from the consumers for grid operations, many new applications can also use AMI. These applications could be consumption monitoring and detection of tempering, loss reduction and efficiency improvements, access to energy for the masses, renewable energy integration into the grid, peak load management through demand forecasting, system improvements and outage optimization management and customer services (Caropreso et al. 2018, Wang et al. 2018, Si et al. 2021).

Traditionally, electromechanical meters or basic electronic meters have been conventionally used to measure energy consumption (Jain et al. 2014, Al-Badi et al 2020). This type of meters requires the transportation of suppliers to the energy meter location for meter readings and other management tasks, e.g., meter disconnection. However, taking into consideration the high number of customers, this is quite exacerbating (Carratu et al. 2018). Smart meters have recently gained a substantial popularity for calculating, controlling and measuring power, gas and water consumption (Kabalci 2016, Morello et al. 2017). Therefore, smart meter is used to record and transmit the gathered information of electricity, water or gas consumption from consumer to utility. The data is normally stored in a server for further operations like calculating consumption fees, displaying dissipation statistics or reporting other information to the customer (Caropreso et al. 2018, Dileep 2020). Hence, based on the processed data, significant energy efficiency and financial savings are expected to be achieved (Caropreso et al. 2018). The massive amount of data generated by the large-scale installations of smart meters, can therefore offer a unique insight of the power consumption of different consumers to the company. This information can be used to help customers to shift their consumption from peak hours, resulting in notable savings of the energy (Jordehi 2019, Hafeez et al. 2019, Irtija et al. 2020). Furthermore, it can help electricity scheduling to facilitate safe and efficient operation of the power system. Recently, there has been an upsurge in adopting smart grid and smart meters by smart cities. Smart homes are major blocks of smart cities. Deployment of Smart meters in residential homes would facilitate automation of homes which is a transition towards Smart homes and eventually Smart cities.

Smart meters can detect tampering and theft attempts. The meters will recognize and $\log$ any invalid attempts or breaches of the security features (Cebe and Akkaya 2021). Mainly, there are three categories of recognition tactics, including, categorizationbased approach, monitoring state based approach and game theory-based approach (Vineeth et al. 2021). Additionally, the meter can send warning messages when the meter is mishandled; software can flag meters that show a pattern of outages that are not consistent with neighboring meters; and sensors on distribution transformers can compare load to meter readings to locate any inconsistencies. Remote programming means utilities do not need to dispatch technicians for on-site firmware upgrades. Since AMI is a versatile technology, vendors will likely release new software versions frequently, and each AMI network can be updated via programmable links (Carratu et al. 2018). Backward compatibility enables utilities to install and use smart meters with older 
technology such as AMR devices and then install the rest of the AMI network as funding and scheduling allow (Caropreso et al. 2018, Akre and Rajan 2020). There is a possibility for meters equipped with ZigBee radio or a similar feature to support in-home networks to further educate and empower the end user (Mir et al. 2019). Finally, bi-directional metering could allow for net metering. Customers with renewable generation (e.g., electricity from solar panels or wind turbines) can potentially feed excess electricity back into the grid and receive monetary payment or credits on their bill from the utility. The meter tracks how much utility electricity the customer uses and how much energy is supplied to the utility from the customer.

Considering strategies towards a sustainable and competitive electricity market in building smart homes, many countries have been advised to mandate utility companies to rollout smart meters to residential customers (Hopf et al. 2018, Al-Turjman and Abujubbeh 2019). This echoes with the proceedings of the National Energy Policy of 2015 on energy efficiency and conservation within electricity sub-sector (NEP 2015). The purpose of this study is to summarize the status of current smart meter deployment initiatives in Tanzania. This paper presents the findings from a survey that was sent to the national utility company. The survey provided information such as number of meters deployed (for residential, commercial, and industrial use), cost, tariff schemes, features, benefits (financial- and performance-based for customer and power companies), and challenges. Emphasis was given to the successes and challenges the company faced during deployment. This study aimed at bringing awareness to the electricity community of the overall progress across Tanzania towards development and deployment of Advanced Metering Infrastructure (AMI) systems and their prospected impacts on household applications.

\section{Materials and Methods \\ Research Methodology}

To determine the status of smart meter deployment in Tanzania, a qualitative research methodology approach was selected. The research data were obtained through the interview process, site visits and questionnaires used during the study at the national utility company offices in Kinondoni Municipality. Kinondoni is one of the five municipalities in Dar es Salaam City. This municipality was strategically chosen due to the ongoing pilot projects of installing power system operation and supervisory control and data acquisition systems (SCADA). The system is for centralized control applications to achieve wide monitoring, planning and optimization for reliable and cost-effective operation of the power system countywide. SCADA is for collection of measurements and status data from the processes. The processes are generation, energy and business management. The data collection process utilized questionnaire sets to acquire information on the current status of deployment of smart meters, services they offer and problems experienced with the delivery process of these smart meters. The content of the questionnaires focused on the main operational components and/or features, tariffs, vendors, cost, mode of operation, networking and business support services. The information gathered was used to propose for the possibility of adopting online smart meter model for residential homes based on the needs identified from the questionnaires.

The last step was to discuss the proposed management model with the expert members of the automatic meter reading (AMR) management and staff before computerizing the smart meter model. The data obtained during this process through interviews and informal discussions were used to support the concept of online smart meter model for household applications. The concept of online prototype model was shared among the interviewers and the data obtained through questionnaires and interviews were then used as inputs towards refining the prototype model. The prototype model should be adaptable to any household electricity 
metering needs. The technical details, testing and validation of the proposed prototype are beyond the scope of this paper. The testing and validation will be in the future works.

The participants for this study included both the management $(n=3)$ and the staff $(n$ $=50$ ) at the national utility company offices in Kinondoni Municipality. The consulted management and staff came from Automatic Meter Reading (AMR) department. They each had to complete a questionnaire and focus group interviews were conducted to clarify and verify certain information. It is important to understand that what was done during this study, was to conduct interviews and questionnaires to determine the status of deployment of smart meters, success and challenges and prospected needs of the industry and community in the development of a prototype that was responsive to specific community's needs and circumstances. These needs targeted Tanzanian household power consumption in the distribution network. This means that the results are not necessarily applicable to other communities in different countries, unless exactly the same needs and circumstances apply. What exists is an electronic model that can be introduced into a new society and then fine-tuned to the needs and circumstances of that new society by means of a similar process.

\section{Framework for Analysis of Deployment Status}

Specific interview questions and openended questionnaires were designed to elicit insight on the processes followed by utility company to install smart meters to their customers. The questionnaires were aimed at establishing the current status of deployment and services that the utility company offers its clients under specific categories or key operation components. Table 1 shows types of customers and their consumption categories. This list was key to establish the deployment status. Deployment of Smart meters started in 2007 as pilot study and later full deployment project was launched in 2009. It has been eleven years of installing Smart metering system to various customers in Tanzania. The major proportion has been given to larger consumers of electrical power.

The customers in $\mathrm{T} 1$ tariff include residential and large customers who meet energy consumption of less than 7,500 Kwh per month. It should be noted that the utility company does not have residential customer category, instead ranks power consumption into tariffs $\mathrm{T} 1, \mathrm{~T} 2$ and $\mathrm{T} 3$ as shown in Table 1. T2 are large customers like medium industries and large buildings. T3 are extralarge customers like Gold and Tanzanite mines and large industries. These customers are usually connected from the $33 \mathrm{kV}$ lines. Table 2 summarizes the status of deployment of the Smart meters done by the utility company for the whole country as of April 2021.

Table 1: Customer consumption clusters

\begin{tabular}{llll}
\hline Tariff category & Energy $(\mathrm{Kwh})$ & Power (KVA) & Connection type \\
\hline Tariff 1 (T1) & $<7,500$ & 0 & Single and three phase \\
Tariff 2 (T2) & $\geq 7,500$ & $<500$ & Large customer $(11 \mathrm{kV})$ \\
Tariff 3 (T3) & $\geq 7,500$ & $\geq 500$ & High tension $(33 \mathrm{kV}$ and above) \\
\hline
\end{tabular}


Table 2: Smart meters countrywide deployment to customers' clusters

\begin{tabular}{llccc}
\hline Connection type & $\begin{array}{l}\text { Smart meter } \\
\text { category }\end{array}$ & $\begin{array}{c}\text { Tariff } \\
\text { category }\end{array}$ & $\begin{array}{c}\text { Number } \\
\text { deployed }\end{array}$ & $\begin{array}{c}\text { Percentage } \\
(\%)\end{array}$ \\
\hline Single phase & Residential & T1 & 0 & $0 \%$ \\
Three phase & Prepaid & T1 & 40,450 & $100 \%$ \\
Three phase & Post paid & T1 & 41,222 & $100 \%$ \\
High tension & Smart meter & T2 & 3,267 & $100 \%$ \\
High tension & Smart meter & T3 & 878 & $100 \%$ \\
\hline
\end{tabular}

Table 2 shows that residential customers falling into $\mathrm{T} 1$ tariff category have not been installed with Smart meters. There are more than six million customers in the distribution network who are connected with single phase. These customers account for more than $80 \%$ of all electrical energy consumers.

Table 3 shows cost range of the Smart meters currently installed into customer premises in Tanzania. Customers and utilities are usually motivated to invest in Smart meters because of the economic advantages in payback time and reduced operational costs. The most significant savings could come from flattening the load curve and saving money from reduced peak loads. After tracking their expenditures over the duration of their Smart meter deployment programs, customers can save in the range of 5-10 percent of their total yearly bill by using Smart meters to implement Demand Response (Nan et al. 2017, Hafeez et al. 2019, Darby 2020). The demand response (DR) is defined as changes in electric usage by demand-side resources from their normal consumption patterns in response to changes in the price electricity over time. Demand response reassures the customers to offload non-essential consumption of electricity during the peak hours, and thus effectively manage the supply of electricity in a balanced way (Yan et al. 2018). However, the two advantages could hardly be achieved in Tanzania if the current Smart meters were to be installed into residential homes. Table 3 shows that average price of smart meter is $\$ 600$ whose return of investment would take longer than expected. The longer it takes to break through in the investment, would precipitate maintenance costs and possibly replacement for efficient newer versions. Acknowledging this fact and the vastness of distribution electrical power network, the needs to adapt a low-cost Smart meter customized to Tanzania household needs are of utmost importance.

The results on the Smart meter features are summarized in Table 4 with the key operational areas listed in the left column and the services offered within the specific operational areas listed in the right column.

Table 3: Smart meter costs

\begin{tabular}{llcc}
\hline \multicolumn{1}{c}{ Connection type } & Smart meter category & Tariff category & $\begin{array}{c}\text { Cost in US } \\
\text { Dollars (\$) }\end{array}$ \\
\hline Single phase & Residential & T1 & - \\
Three phase & Prepaid & T1 & 440 \\
Three phase & Post paid & T1 & 440 \\
High tension & Smart meter & T2 & 570 \\
High tension & Smart meter & T3 & 1050 \\
\hline
\end{tabular}


Table 4: Smart meter features and service offered

\begin{tabular}{|c|c|}
\hline Smart meter feature & Services offered \\
\hline Two-way communication & $\begin{array}{l}\text { Communication between System and customer } \\
\text { equipment (Smart meter) }\end{array}$ \\
\hline Data recording capability & $\begin{array}{l}\text { Storage retrieval and storage from Smart meter } \\
\text { to System. Retrieval is done in the interval of } \\
10-20 \text { minutes. }\end{array}$ \\
\hline Integrated remote disconnection switch & $\begin{array}{l}\text { Remote disconnection of the Smart meter by the } \\
\text { System }\end{array}$ \\
\hline Home Area Network interface & $\begin{array}{l}\text { Support of the interconnection with local } \\
\text { devices and applications for automation }\end{array}$ \\
\hline Data storage capability for blackout & Prediction and forecast \\
\hline Automatic Voltage and current restore & $\begin{array}{l}\text { Restoration of standard acceptable values for } \\
\text { safety and reliability }\end{array}$ \\
\hline Secured data communication infrastructure & Data collection and firmware updates \\
\hline Remote billing & Billing subsystem \\
\hline
\end{tabular}

Active and reactive power control

Energy theft protection

Demand Side Management

Demand Response

To avoid tempering or theft of electrical power

Home automation to save energy and reduce

cost

Top-up capability

Alarm control

Topping up using public networks

Multi-tariff control

For monitoring and control

Customized demand response

Programming

Remote firmware installation and upgrading

The features of the Smart meter applications usually dictate the price of the device. Although all installed Smart meters provide the previously mentioned features, almost all of them provide the AMR functions such as detailed consumption storage. Moreover, they provide improved remote monitoring and control capabilities by twoway communication, instant data acquisition and remote billing requirements. In Figure 1, the percentage usage of the features in the currently installed Smart meters is reviewed. The review is done on the customer usage categories of Tariffs 1,2 and 3 .

The review on the usage of the features usually reflects the services the Smart meters provide to the customers and the utility. It is through usage of features where developers refine their designs to fit with the actual needs of the customers. To accommodate all residential customers with smart meters, millions of devices will have to be purchased by the government to fill the gap on the residential home's energy metering. It is therefore, significantly important to revisit the Smart metering technologies which fit our needs and reduce costs. The latest Smart metering researches have been dealt with power quality issues such as automatic voltage restores, frequency and voltage control, active and reactive power control, demand side management, demand responses, decentralized generation in the context of microgrid and cyber-secure communication systems. Table 5 shows the different vendors suppling Smart meters to the national utility company. EDMI supplies all of the T1 and T2 Smart meters, while the rest supply the T3 Smart meters. 


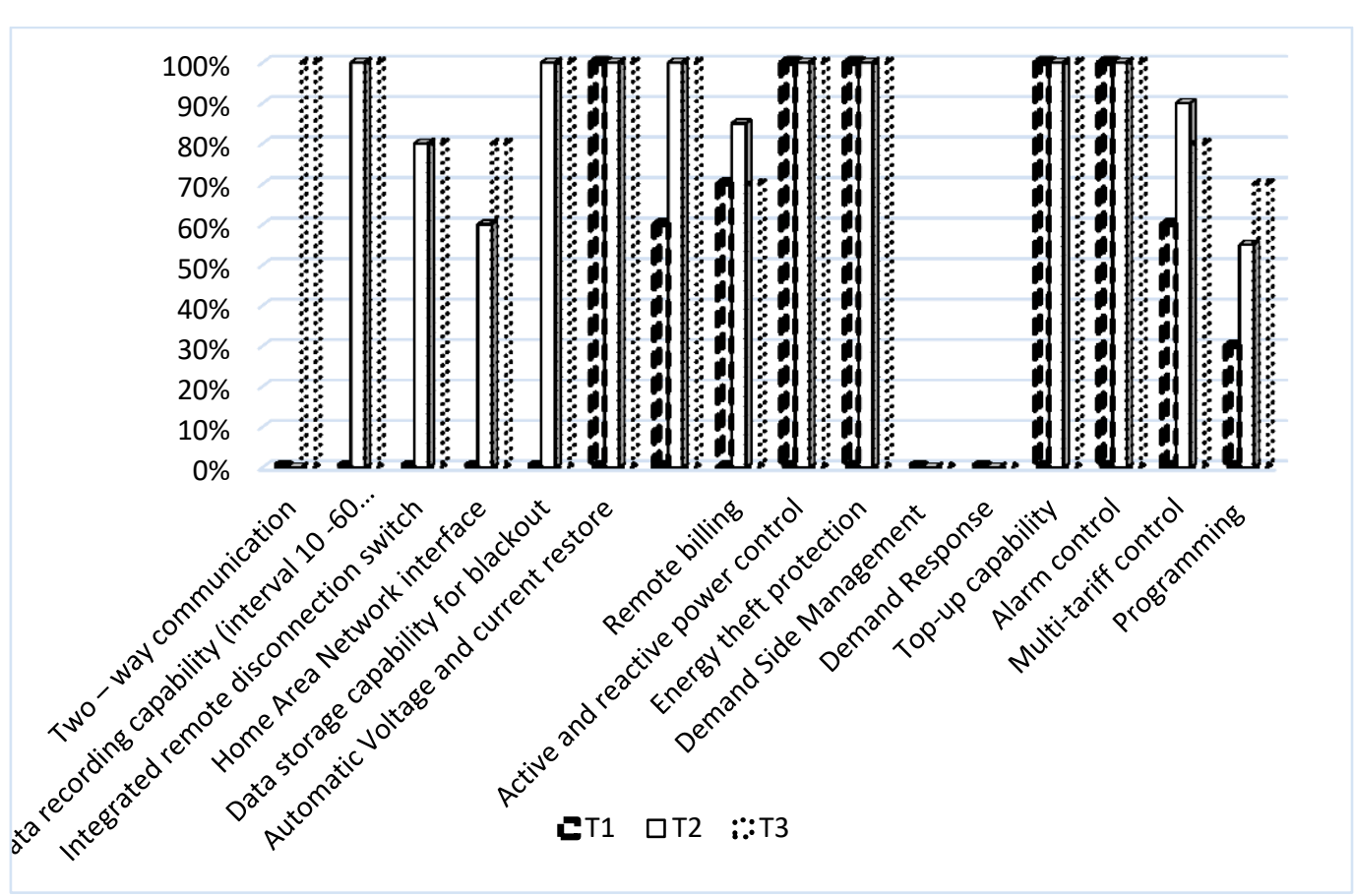

Figure 1: Percentage usage of the Smart meter features

Table 5: Smart meter vendors

\begin{tabular}{lll}
\hline Smart meter category & Vendor & Market share \\
\hline Tariff 1 & EDMI & $100 \%$ \\
Tariff 2 & EDMI & $100 \%$ \\
Tariff 3 & EDMI, & $10 \%$ \\
Tariff 3 & Wasion & $10 \%$ \\
Tariff 3 & Inhemeter & $10 \%$ \\
Tariff 3 & Comfix, HEXING & $10 \%$ \\
\hline
\end{tabular}

Further, the authors inquired on the challenges on the deployment of Smart meters and the underlying systems. Table 6 shows the technical and non-technical challenges on the deployment exercise.

The results in Table 6 communicate that communicating using public networks is risky to customers as intruders could penetrate and access the consumption data easily. The utility company should begin communicating its intentions to introduce Smart meters to single phased customers, before the deployment of meters begin to ensure success of the projects, avoid customer resistance.
The utility should bear in mind that customer satisfaction begins with customer communication and education. There are many pitfalls associated with the absence of, or misdirected communication. Positive examples of communication that can be considered by utility include web portal implementation, advance customer notifications and customer education sessions. The utility will have to be innovative and extend the traditional communication channels with digital supplements such as Twitter and Facebook. 
Table 6: Challenges on the deployment of Smart meter

\begin{tabular}{ll}
\hline Technical & Non-technical \\
\hline Cyber attacks & Power theft and meter tempering \\
Lack of skilled technical personnel & High cost \\
Standards (i.e. interoperability) & Low public awareness \\
Security threats of using public networks & User functionalities \\
\hline
\end{tabular}

\section{Results and Discussion}

Management and staff of AMR department at the utility company were asked: 'What are the major reasons for $0 \%$ Smart meter installation into single phased customers as observed in Table 2?' The responses were the following:

- The government prioritized three phased to larger customers instead of single phased customers who are mostly residential homes in the secondary distribution network

- To accommodate small scale consumers in the secondary network, a fully functioning AMI network is needed. Currently, SCADA and AMI technologies are being installed to lay down the supporting network infrastructure.

- The low return on investment (ROI)

The responses of the management and staff of the AMR department from the main electrical power stakeholder, the national utility company, indicated cost and technical unpreparedness to invest in smart meters for single phased residential homes. Likewise, the responses of the management and staff of the AMR department, supported by stats in Table 2 and Table 3, indicate the need to customize the features and design a low-cost Smart meter for household applications in Tanzania becomes palpable. The analysis on usage statistics in Table 1 reveals that all of the meters that were installed on residential buildings were from three phased customers. The rest were on larger buildings and industries whose electricity and energy consumptions were above $7,500 \mathrm{kWh}$ and 500 KVA, respectively. The most commonly used meter brand was EDMI with approximately 60 percent of the Tanzanian market share and various companies as shown in Table 5 split the remaining percent. All Smart meter's report using interval reads and tamper/theft detection on their feeds and all are utilizing the remote connect/disconnect feature. None of the meter's use in T1 category use meters' outage detection feature, while 80 percent use the data recording and communication link features. None of the meters in T1, T2 and T3 category utilize the demand side management and demand response. The top-up capability, multi-tariff control are features supported by the system. But they are not utilized as they await approval from the regulator, Electricity and Water Regulatory Authority (EWURA) to be affected. These findings follow the trend that the utility took advantage of the government funding to install Smart meters, and chose to implement the rest of the AMI network in the second stages of its project before investing in single phased customers. This also highlights on the need of standards on the Smart metering devices and technology. Given that different parts of the smart grid device and technologies are being developed by different manufacturers, it is necessary to pay attention to the standardization of the format of messages and methods of data exchange. Currently in Tanzania there is no official standardization document of the Smart metering or Smart grid technologies to guide and inspect the importation and manufacturing of the same.

The authors advise that proprietary systems should be avoided by the utility to ensure interchangeability between suppliers in certain areas. Most of the AMI systems employed in the world have their own propriety protocols and designs and interchangeability will be almost impossible. Major manufacturers are currently working on standardization of communication protocols to allow for interchangeability of components at installed AMI systems. Utility should only procure Smart meters from suppliers with standards that conform to the need for interoperability. Only systems that 
conform to standards issued by an official standardization organization, Tanzania Bureau of Standards (TBS) could offer the guarantee that there are no hidden intellectual property rights (IPRs), and therefore lack of interchangeability, attached to it.

\section{Conclusion}

The increased reliability brought by Smart meters' deployment is another means to save money to low-income earners. These lowincome earners are mostly expected in the secondary distribution networks with single phase connections. The AMI systems could allow utilities to target outages to minimize the affected area and restore power faster. Additionally, operational costs are decreased because Smart meters enable many tasks to be done remotely and utilities can downsize their technician fleet. It has been declared as a policy of the Tanzanian Energy Policy of 2015 to modernize the electricity transmission and distribution system to maintain a reliable and secure electricity infrastructure that can meet future demand growth and to achieve each of the following, which together characterize a Smart Grid. These items summarize the technical merits of Smart Grid infrastructure in terms of characteristic features. The digital control and information technologies are widely used in Smart Grid applications to increase reliability, security, and efficiency of power grid. It was wellknown that security of this cyber-physical system (CPS) is depended to dynamic optimization of grid operations and sources. Therefore, demand response (DR), demand side management (DSM), deployment of distributed source in generation and deployment of smart technologies such as remote monitoring, advanced metering, and distribution automation control have been described as crucial characteristics of a Smart Grid system. In addition to contributions in generation, transmission, and distribution systems; the authors advise that consumption level should also be considered in the reviewed Energy Policy and Electricity Act of 2007. The consumer devices and appliances should be converted to smart ones, while improving the existing power grid.

\section{References}

Abate F, Carratù M, Liguori C and Paciello V 2019 A low cost smart power meter for IoT. J. Int. Meas. Confed. 136: 59-66.

Al-Badi AH, Ahshan R, Hosseinzadeh N, Ghorbani R and Hossain E 2020 Survey of smart grid concepts and technological demonstrations worldwide emphasizing on the Oman perspective. Appl. Syst. Innov. 3(1): 1-27.

Al-Turjman F and Abujubbeh M 2019 IoTenabled smart grid via SM: An overview. Future Gener. Comput. Syst. 96: 579-590.

Akre LV and Rajan AV 2020 Benefits of open source software (OSS) tools for smart city projects. Int. J. Adv. Sci. Technol. 29(5): 552-563.

Avancini DB, Rodrigues JJPC, Rabêlo RAL, Das AK, Kozlov S and Solic P 2020 A new IoT-based smart energy meter for smart grids. Int. J. Energy Res. 45(1): 189202.

Caropreso RT, Fernandes RAS, Osorio DPM, and Silva IN 2018 An Open source framework for smart meters. IEEE Trans Industrial Electronics. 66(2). 1638-1647.

Carratu M, Ferro M, Pietrosanto A and Paciello V 2018 Smart power meter for the IoT. IEEE $16^{\text {th }}$ Int. Conf. Ind. Inf. 514-519.

Cebe M and Akkaya K 2021 Communicationefficient certificate revocation management for Advanced Metering Infrastructure and IoT Integration. Future Gener Comput. Syst. 115: 267-278.

Darby SJ 2020 Demand response and smart technology in theory and practice: Customer experiences and system actors. Energy Policy 143: 111573.

Dileep G 2020 A survey on smart grid technologies and applications. Renew. Energy 146 (C): 2589-2625.

El Houda ZA, Hafid AS and Khoukhi L 2020 Blockchain Meets AMI: Towards Secure Advanced Metering Infrastructures. IEEE Int. Conf. Commun. 1-6.

Hafeez G, Islam N, Ali A, Ahmad S, and Alimgeer MU and KS 2019 A modular framework for optimal load scheduling under price-based demand response scheme in smart grid. Processes 7(8): 499. 
Hopf K, Sodenkamp M and Staake T 2018 Enhancing energy efficiency in the residential sector with smart meter data analytics. Electron. Markets 28(4). 453473.

Irtija N, Sangoleye F and Tsiropoulou EE 2020 Contract-theoretic demand response management in smart grid systems. IEEE Access 8: 184976-184987.

Jain S, Vinoth KN, Paventhan A, Kumar Chinnaiyan V, Arnachalam V and Pradish M 2014 Survey on smart grid technologies-smart metering, IoT and EMS. IEEE Conf. Electr. Electron. Comput. Sci. 1-6.

Jordehi AR 2019 Optimisation of demand response in electric power systems, a review. Renew. Sustain. Energy Rev. 103: 308-319.

Kabalci Y 2016 A survey on smart metering and smart grid communication. Renew. Sustain. Energy Rev. 57: 302-318.

Mir SH, Ashruf S, Bhat Y, Sameena and Beigh N 2019 Review on smart electric metering system based on GSM / IOT. Asian J.l Electr. Sci. 8(1): 1-6.

Mohassel RR, Fung AS, Mohammadi F, and Raahemifar K 2014 A Survey on Advanced Metering Infrastructure and its Application in Smart Grids. IEEE Canadian Conf. Electr. Comp Eng. 1-8.

Morello R, De Capua C, Fulco G, and Mukhopadhyay SC 2017 A smart power meter to monitor energy flow in smart grids: The role of advanced sensing and iot in the electric grid of the future. IEEE Sens. J. 17(23): 7828-7837.

Nan S, Zhou M, and Li G 2017 Optimal residential community demand response scheduling in smart grid. Appl. Energy. 210: $1280-1289$.

Omole OS, Akpobasah D, and Atayero AA 2016 Development of a smart, low-cost and IoT-enabled system for energy management. Int. Conf. Afr. Dev. Issues 150. 401-406.

PSMP 2020 Tanzania Power System Master Plan. Ministry of Energy.

Si C, Xu S, Wan C, Chen D, Cui W and Zhao J 2021 Electric load clustering in smart grid: methodologies, applications and future trends. J. Modern Power Syst. Clean Energy 9(2): 237-252.

NEP 2015 Tanzania National Energy Policy. Ministry of Energy.

Vineeth VV, Ambrish V, Haricharann DV, Harshini V and Abilash C 2021 Power theft recognition and data security in smart meter reading of a smart grid. $J$. Phys.: Conf. Ser. 1916(1): 012216

Wang Y, Chen Q, Hong T and Kang C 2018 Review of smart meter data analytics: applications methodologies and challenges. IEEE Trans Smart Grid. 10(3). 3125-3148.

Yan X, Ozturk Y, Hu Z, and Song Y 2018 A review on price-driven residential demand response. Elsevier Renew. Sustain. Energy Rev. 96: 411-419. 